\title{
Caregivers' Perspectives on the Determinants of Dietary Decisions in Six First Nation Communities.
}

\section{Lorrilee McGregor, M.A.}

School of Rural and Northern Health Laurentian University, 935 Ramsey Lake Road, Sudbury, Ontario, P3E 2C6, le_mcgregor@laurentian.ca

Dr. Pamela Toulouse, PhD.

Associate Professor Faculty of Education Laurentian University, ptoulouse @laurentian.ca

Dr. Marion Maar, PhD.

Associate Professor Northern Ontario School of Medicine, 935 Ramsey Lake Road, Sudbury, Ontario

P3E 2C6, marion.maar@nosm.ca

Dr. Nancy L. Young, PhD.

Full Professor School of Rural and Northern Health, Laurentian University, nyoung @laurentian.ca

Follow the International Journal of Indigenous Health at:

https://jps.library.utoronto.ca/index.php/ijih/index

\section{Recommended Citation:}

McGregor, L., Toulouse, P., Maar, M., Young, N. L. (2018). Caregivers' perspectives on the determinants of dietary decisions in six First Nation communities. IJIH, 13(1), 122 - 139.

https;//doi.org/10.18357/ijih.v13i1.30306 


\title{
Caregivers' Perspectives on the Determinants of Dietary Decisions in Six First Nation Communities.
}

\begin{abstract}
Colonialism is a fundamental determinant of Indigenous people's health in Canada, yet little is known about its effects on food systems and dietary decisions in First Nation communities. A socioecological approach was used to explore the determinants of dietary decisions made by Indigenous caregivers. Conclusions are drawn from a narrative analysis of eight focus groups involving 33 caregivers in six First Nation communities. Caregivers identified the changes that they have observed in how food is procured, distributed, processed and prepared, along with the nutritional consequences and the sociocultural meanings of these changes. Determinants such as participation in the wage economy, low income, hunting and fishing regulations, availability of fish and game, and the proliferation of inexpensive, processed foods have altered the food systems and influenced dietary decisions made by caregivers in six First Nation communities. Initiatives such as community gardens, community freezers and community hunting camps are ways that these communities are seeking to regain food sovereignty.
\end{abstract}

\section{Keywords}

Indigenous health, nutrition, socioecological approach, determinants of health, colonialism

\section{Creative Commons Licence} @) $\Theta \Theta \Theta$

This work is licensed under a Creative Commons Attribution-Noncommercial-No Derivative Works 4.0 License. 


\section{Introduction}

Poor nutrition has been identified as a barrier to good health among Indigenous children in Canada. Dietary gaps such as not meeting recommendations for daily consumption of fruits and vegetables are critical examples of this issue (Earle, 2011). Obesity and other health outcomes such as anemia, dental caries, heart disease and diabetes have also been linked to poor nutrition among Indigenous populations (Willows, 2005). Poor nutrition is a result of dietary decisions which are influenced by a complex social and political environment. Dietary decisions are made by individuals but need to be considered within a food system. A food system refers to the processes that affect how food is acquired and processed as well as the socio-cultural meanings surrounding food (Willows, 2005). Understanding the determinants that influence food systems in First Nation ${ }^{1}$ communities is essential to addressing poor nutrition and preventing negative health outcomes. In this paper we draw from a socioecological approach (Willows, Hanley \& Delormier, 2012) that reflects the insights of 33 caregiver participants. Focus groups were conducted to understand how food systems in six rural First Nation communities have changed and to identify the determinants that influence dietary decisions.

\section{Food Systems and Indigenous Peoples}

Indigenous peoples are the fastest growing population in Canada. In 2006, about one-third of this population was under the age of 15 (Statistics Canada, 2008). This young and rapidly growing population is perhaps the first generation of Indigenous peoples who have not relied on traditional foods as an integral component of their diet. Kuhnlein (2005) defined traditional foods as, "those foods that Indigenous Peoples have access to locally, without having to purchase them" (p. 3) while market foods are, "those foods that enter communities often through global industrially sponsored retail outlets, and which must be purchased (e.g. sugar, oil)" (p. 4).

Food is an important way of expressing culture through the methods used to acquire it, the values around how it is distributed and the ways in which it is prepared (Willows, 2005). Food is also linked to the maintenance of social relationships and is important to cultural identity. Willows (2005) states that, "the consumption of traditional foods is more than just about eating; it is the endpoint of a series of culturally meaningful processes..." (p. s33). Traditional food systems have been recognized as being significant for the holistic health of individuals and communities (Kuhnlein, 2009).

Food systems in First Nation communities have been disrupted by colonial policies. For example, in the 1880's, government agents would limit rations as a way of punishing First Nation communities or to coerce Indigenous leaders into signing treaties so their people would not starve (Dickason $\& \mathrm{McNab}$, 2009). Access to traditional foods was compromised over generations through the loss of traditional lands. Indigenous peoples were discouraged from their traditional ways of obtaining food such as

\footnotetext{
${ }^{1}$ The term 'Indian reserve' has been rejected and communities have renamed themselves as First Nations to reflect their position as the first inhabitants of North America (NAHO, n.d.).
} 
hunting and gathering and encouraged to take up farming (Dickason \& McNab, 2009). This was particularly challenging in areas where the land was not suitable for agriculture. However, when Indigenous people were able to farm the land successfully the government would introduce regulations making it difficult to sell their produce or to invest in new technology (Dickason \& McNab, 2009). At present, hunting and fishing regulations limit access to traditional foods through the requirements of costly licensing and enforcement.

The Indian residential school system disrupted family learned processes of preparing foods that had been handed down for generations (Willows et al., 2012). Residential school survivors have reported on the limited amount of food and the poor quality of food available to them as students (Truth and Reconciliation Commission of Canada, 2012). Students were expected to work in the gardens but often times were not allowed to partake in the fruits of their labour (Truth and Reconciliation Commission of Canada [TRC], 2012). Hunger was rampant and students often had to resort to stealing food in order to survive (TRC, 2012). Students longed for their traditional foods, but instead were fed unfamiliar foods such as pasta and processed meat (TRC, 2012). Dismal conditions at many residential schools were viewed as an opportunity to study the effects of malnutrition and to "assess the adaptability of a diet that was making its supposedly inevitable transition from 'traditional' to 'modern"' (Mosby, 2013, p. 161).

These ongoing assaults on Indigenous food systems over generations have resulted in a transition from a traditional diet that was high in omega- 3 fatty acids, low in carbohydrates, and rich in micronutrients, to a diet of market foods which is high in trans-fatty acids and carbohydrates, and low in nutrients (Earle, 2011; Willows, 2005). Understanding the impact of this transition on dietary decisions made by caregivers in six First Nation communities is the focus of this paper.

\section{Methods}

The research described in this paper contributes to a larger mixed-methods study seeking to understand health behaviours and obesity among Indigenous children in six First Nation communities. Community consent for this study was granted by all six First Nation band councils and ethics approval was obtained from the university Research Ethics Board. This topic was identified by Elders, health care workers and teachers within this region as a health priority. This paper reports on the perspectives of caregivers about the dietary decisions made in their households.

\section{Data Collection}

Participants in this study were mainly caregivers (i.e., parents or grandparents) of First Nation children and interested community members. Participants were invited through fliers that were sent home with students in the First Nation schools and through posters in the community. In the communities that did not have an elementary school, parents and guardians were mailed an invitation to participate. 
Focus groups took place either at the community health center or in First Nation schools. Written consent to participate, and oral consent for audio-recording, was obtained prior to the start of the focus groups. Semi-structured and open-ended questions focused mainly on how and why nutrition has changed from the past to the present. All focus groups were conducted in English, and lasted between 90 and 120 minutes. A total of 33 caregivers participated in the focus groups (23 mothers, 4 fathers, and 6 grandparents or guardians). Most participants were women $(n=28)$.

\section{Analysis}

The focus groups were facilitated by the lead author, an Indigenous doctoral student and a member of one of the participating First Nation communities, thus giving the author an insider perspective along with particular biases. Given the personal, professional and educational background, the lead author has a dual perspective or what has been described as 'two-eyed seeing' (Bartlett, Marshall, \& Marshall, 2012). This refers to understanding the world from both an Indigenous and a Western perspective. The lead author was supported by both Indigenous and Western scholars with extensive research experience in children's health and First Nation communities.

This paper draws from a narrative analysis of focus groups with 33 caregivers of Indigenous children in six First Nation communities. Audio-recordings from the focus groups were transcribed and then imported into NVivo 10. The transcripts were reviewed for both surface level content, as well as underlying meanings (Babbie, 1992). Segments of data were coded with a label that categorized and summarized the data (Charmaz, 2006). Two member-checking sessions with some of the participants were held to solicit insight into the findings. Further analysis involved labelling and sorting the data into themes and sub-themes around the determinants that influenced the dietary decisions of participants.

\section{Results}

Dietary decisions were found to be influenced by interpersonal, community, and societal level factors as well as historical influences. In this study it was important to hear the voices of the participants who articulated their perceptions around food and nutrition. There were extensive discussions about how food has been procured, contrasting food from the land with market food from the grocery store. Food distribution was affected by the availability of game and fish, high costs, food quality, and transportation challenges. The processing and preparation of food is influenced by time, skills, availability of processed foods, and personal preferences. The health consequences of consuming certain types of food were of concern to the caregivers. Finally, participants referred to sociocultural beliefs around identity, feeling 'lazy', and the value of sharing.

\section{Food from the Land}

Participants recalled a time when they relied on 'food from the land' for a substantial portion of their diet as illustrated by this comment: "It was more off the land - land-based type food. And we went with the seasons. Whatever was growing we picked and we ate." Land-based food includes wild game, 
fish, vegetables from gardens and wild fruit. Participants described the methods for procuring food from the land such as hunting and fishing, gardening, harvesting, and raising livestock.

\section{Hunting and Fishing}

Hunting and fishing remain culturally significant activities in all participating communities. Participants reported that large game like moose and deer continued to be widely available, however small game such as rabbit and partridge, are scarce. Participants also reported that the indigenous fish stock has drastically declined limiting consumption. Due to limited access to certain types of game and fish, some participants reported that they only eat them at feasts. One of the participants commented on the availability of freshwater fish, "I think there's fewer fish out there. When we used to go fishing we used to catch a lot of fish" (Sally, participant). As small game and fish are scarce, participants noted that it took longer to acquire them resulting in a focus on large game like deer and moose. Government regulations also limit when and where hunting and fishing activities can take place. Although there are treaty rights to hunt and fish, these practices continue to be infringed upon. An example of this occurred in a sting operation conducted by the Ontario Ministry of Natural Resources when their agents entrapped Indigenous hunters into selling wild game (DiGangi, 1993). This approach to fish and wildlife enforcement by the government was noted by one of the focus group participants:

They got so much regulation now that they govern, that they want to make sure that they got you. If you can live independently, then they can't govern you. Live off the grid. They make sure, they could take your licence away, they could take a lot of things. The government's got a hold of people now. (Ryan, participant).

\section{Harvesting}

Participants recalled picking different types of berries for personal consumption or to supplement their income. In the spring families would make maple syrup and apples were picked in the fall apples. Preserves, like jams and pickles, would be made from the foods they harvested, "My mom was a gatherer. She'd pick raspberries, strawberries, you name it. She got wild plums. She'd make jam out of it, for the winter. All that stuff, even acorns. We saved those too, eh" (Brian, participant). Participants also noted that harvesting fruit has declined in recent years.

\section{Gardening}

Gardening used to be a seasonal activity in these communities. Participants reported that most families had gardens that would supply them with fresh vegetables during the summer months and root vegetables that could be stored for the winter months. One participant stated,

We had a huge garden. I remember weeding and being part of that because we all had to take turns and do our share of it. So we had corn, potatoes, beans, 
turnips ... those kinds of things. Carrots in the garden. My mom did canning. (Addy, participant).

Participants reported that there were fewer households with gardens in their community.

\section{Raising Livestock}

Participants recalled that livestock like chickens, horses, and cows used to be raised in the communities but not many community members do this anymore. One participant noted, "And my mom, she took care of the chickens and made sure we got our eggs. And we had a cow. That's where we got our milk" (Brian, participant). Traditional methods of procuring food from the land were labour intensive and activities like hunting, fishing, harvesting and raising livestock involved all family members.

\section{Food from the Grocery Store}

The shift from land-based food to the grocery store has resulted in significant changes to diets. Grocery stores are between five and 52 kilometres away from these communities with mostly processed foods available in convenience stores within the communities. Participants described the high cost, but poor quality, of fruits and vegetables in their communities, as well as transportation barriers to obtaining food from grocery stores in towns.

\section{Shopping at a Grocery Store}

Participants reported that in the past their families only went to the grocery store once or twice per month and that the foods purchased were generally staples like flour and sugar and other ingredients to prepare meals from scratch. A participant stated, "What I remember is that it was things - like we did very little grocery shopping. So, you know, things that came in a can, a bag of sugar, flour, and stuff” (Addy, participant). In comparison, participants reported that they make more visits to the grocery store where mainly processed foods are purchased. This practice is a significant shift from the past when people relied mainly on whole foods from the land.

\section{Cost}

Market food in rural Ontario is expensive. This was an important consideration in food selection for participants, some of whom had limited incomes and had to ensure that the food they purchased was going to last the entire month. Participants noted difficulties in budgeting in order to afford nutritious foods, "I try to stretch my money as far as I can but still be nutritious" (Sandra, participant). Similarly, other participants noted that the cost of fresh foods is high compared to the amount of food that can be purchased, "You don't get too much for your money now. \$200 worth of groceries doesn't get you much" (Josephine, participant). The high cost of food from grocery stores in rural Ontario affected food purchases with some participants who perceived convenience foods to be less expensive than whole foods. 


\section{Food Quality}

Participants commented on the quality of the fruits and vegetables available in the grocery stores. They recalled instances of fruits and vegetables spoiling quickly. One participant noted, "The stuff we buy [in town] like for me I find if I buy fresh fruit at [the grocery store] and two days later it's like mouldy" (Louise, participant). Other participants supported this as well:

The amount of time we go to get fresh fruits and vegetables. Half the time the lettuce will wilt. So it's basically the shelf life of fresh fruits and vegetables. Sometimes we go for a two-week span then we go get fresh stuff. (Alannah, participant).

Compounding the problem of poor quality fruits and vegetable in grocery stores is that the foods typically available for sale in the communities are in convenience stores and tend to be snack foods like chips or non-perishable food items.

\section{Transportation}

As there is no public transportation available in these communities, those families who do not have a vehicle find that much of their income can be spent on transportation. Because of the high cost of transportation, they made fewer trips to the grocery store requiring the food they purchased to last longer. This limited the purchase of fresh fruits and vegetables, and increased the purchase of shelf stable foods which do not spoil as quickly, but are typically nutrient deficient and/or high in sugar, fat, and salt. A participant reported that transportation is an important factor in access to fresh food:

Cost you twenty bucks just to get to town. Hard to get around to those good vegetables right off the shelf. It just doesn't happen. I get to town maybe once a week if that. So yeah, transportation is a big thing. (Kristan, participant).

Food procurement in the participating communities has transitioned from the land to the grocery store placing community members at risk for food insecurity. Food insecurity is not only impacted by the availability of game and fish but also the cost and quality of food, socioeconomic status and transportation costs.

\section{Processing and Preparation of Food}

The way in which food is processed and prepared influences the nutritional quality of the food. In addition, the type of food that is prepared is often based on food preferences. Participants reported that in the past, meals were prepared from 'scratch', that is, prepared at home, however now there is a greater reliance on processed foods. This marks a shift from meals made from whole foods, to meals prepared with some or all processed food. 


\section{Cooking From 'Scratch'}

As noted, participants reported that in the past, meals that were made 'from scratch' at home used whole food ingredients. These meals tended to be simple meals, such as a serving of meat and potatoes, with other root vegetables (i.e., carrots or turnips) may also be served. Wheat-based products such as bread or cake were also prepared at home. One participant recalled observing this process from their parent:

Well as a kid I remember my mom making everything from scratch like there was roast, there was always potatoes and a vegetable. And now I don't do that so much. I probably do it maybe four days out of the week. Not consecutively. Once in a while I like to keep it balanced and throw, like, French fries or some processed food [laughs]. (Sally, participant).

Some participants reported not having the cooking skills to prepare meals from 'scratch'. Other participants recognized that they should eat more vegetables, but do not have the cooking skills required in order to prepare them. Participants also reported having wild game in their freezer but not knowing how to prepare it:

Like I think we have moose that somebody gave us, from in the winter and, but it's just sitting in our fridge because I don't really know how to cook it. And I know if I try it's going to be awful. (Kristan, participant)

\section{Convenience of Processed Foods}

Participants noted that there has been a transition from meals prepared from whole foods to meals that are a combination of home cooked and processed foods. Some participants preferred processed foods because they don't take as long to prepare. Processed foods, such as frozen pizza, can be heated up quickly, "Not too much wild. Ready-made, throw it in the oven and it's done. Open the box and throw it in there. Chicken fingers and stuff. Fries, hamburgers already made" (Paula, participant).

\section{Personal Preferences}

Participants reported that food choices were made in consideration of their own preferences, and those of children who were 'picky eaters'. In some families, the high cost of food was a deterrent to preparing food that their family does not like. Some participants indicated that they did not like eating wild game or fish because they either had too much when they were young, or were not exposed to it at all and had never acquired a taste for it, "My dad never liked wild meat when we were growing up so we never had it. That's why we were always grocery store people. He wasn't an eater that way so I don't care for it myself now" (Alannah, participant). Similarly, other participants stated they had not grown into eating some foods, "Fish - but I never ate fish. I just could never acquire a taste for it" (Emily, 
participant). In regards to preparing meals for children, one participant noted a need for accommodating their child's tastes:

Especially, too, since it's just me and my son at home. We're both picky eaters, too. Gotta cook what he likes to eat because he doesn't like that deer meat stuff like everyday kind of thing. I gotta cook to his likings, too. (Kristan, participant).

The processing and preparation of food in these First Nation communities has undergone a significant transition. In the past, most food would be acquired from the land and prepared at home, however at present, most food is purchased and reheated rather than cooked. Cooking skills have declined, and participants reported that they do not have time to prepare meals from scratch. Food preferences can be seen as individual choice, however, there is evidence that highly processed foods that are high in fat, sugar, and salt are engineered to be appealing (Moss, 2013).

\section{Nutritional Consequences}

Participants in these focus groups demonstrated that they were knowledgeable about healthy foods by giving examples of meals they had prepared. They also recognized the connection between a poor diet and the risk of developing obesity and diabetes.

\section{Knowledge About Healthy Foods}

Responses from participants indicate that they were knowledgeable about healthy foods:

And me, myself being, I like to cook. I eat everything fresh as I possibly can, like without adding like cans and all that stuff, like, I cut all that stuff off, MSG, anything. Like, I cut all that stuff off. I just keep it right down to the basics.

(Dexter, participant).

Another participant reported also cooking healthy foods for meals, "I basically cook meat, potatoes, vegetables occasionally rice, pasta. Just fruits and vegetables at home" (Alannah, participant).

\section{Health Concerns}

Participants expressed concern about negative health outcomes related to poor food choices. One participant reported the impact that diabetes had in families grocery choices and concerns for the family's health,

We used to, sometimes too, we didn't have food to eat and we mostly ate scone, corn soup. I bet you that's where all the diabetes came from eating salt pork, stuff like that, eh. Because sometimes, you know there was no, like grocery 
stores or we didn't have fridges to keep meat, fresh meat all the time. So I think that's where the diabetes stepped in is when we started eating these kinds of foods eh. Like lot of fried, fried bread, you know scone. Salt pork, I remember eating a lot of salt pork when I was young. (Bernadette, participant).

Attempting to influence children to eat healthy and balanced meals to avoid the development of diabetes was also noted by other participants, "We've started pushing the vegetables on the boys and eating healthy. That's a change for our whole household. That's to prevent diabetes and get them into the habit of it" (Alannah, participant). Similarly, participants noted that they attempted to limit consumption of soda drinks due to familial concerns with diabetes in family units, "I always tell him, no, don't buy pop because of diabetes. It runs in our family" (Kristan, participant).

\section{Sociocultural Meanings}

Acquiring food, selecting what to eat, and preparing food is a complex activity charged with sociocultural meanings. During the focus groups, participants discussed the importance of traditional foods for ceremonies, and how eating traditional foods are important to their Indigenous identity. In addition to not having the cooking skills and preferring processed foods, they also described themselves as too 'lazy' to cook food from 'scratch'. In addition, personal finances have put constraints on the value of sharing.

\section{Ceremonial}

Traditional foods like wild game were seen as important for ceremonies like feasts, and described as holding special meaning for participants,

... my mom will can venison and so sometimes the only time we'll eat like that, like the older foods is if we're at a feast at my mom's house or, and then again, she won't make venison stew on a Tuesday. It's almost something special now like you have it after a sweat lodge or something. She'll have venison or like that kind of meat. But I wouldn't make it on like a Wednesday. It's like a special thing for me now. (Sandra, participant).

Often, these traditional foods are reserved for special occasions like feasts or ceremonies due to the skill and time required to prepare such foods.

\section{Identity}

Eating traditional foods such as wild game was seen as important to cultural identity: So every once in a while I don't mind some game meat or stuff like that just for you know, a change of scenery or a change of diet or what not. But we don't, we don't eat as much as we probably should, as Indians. (Rodney, participant). 


\section{'Lazy'}

Some participants described themselves as 'lazy' when they relied on convenience foods for meals. One participant explained,

It's just that after a day at work then you get home and it's like, ugh, I don't feel like doing the whole food prep of doing a big meal so I throw a pizza in the oven or we'll order a pizza whatever the case may be. But there's nights where I... same thing that lazy mode like, ugh [laughter]. (Sally, participant).

When probed, two reasons were given for describing themselves in this way: firstly, participants reported feeling tired upon arrival home, and secondly, noted they felt they did not have sufficient time required to cook a meal from scratch.

\section{Sharing in Times of Acarcity and Abundance}

Sharing is noted as a fundamental value within this Indigenous group (Power, 2008). Historically, when food from the land was more abundant, participants reported that people would share food more readily within communities. As food from the land has become scarce, the value of sharing has been eroded over time. Even though these First Nation communities have improved socioeconomically, some participants described feeling reluctant about sharing food which is in conflict with social mores, "Because the groceries are pretty expensive these days and nobody really shares" (Agnes, participant). Traditional foods were seen as important for ceremonies and for Indigenous identity among some focus group participants. Sociocultural beliefs around the label 'lazy' and the changing value of sharing stem from historical factors related to colonialism. Lazy is one of the labels that has been attributed to Indigenous people and appears to have been internalized, thus sustaining racist stereotypes and negative perceptions of Indigenous people (Lutz, 2009). Sharing food is a fundamental cultural value, but food insecurity appears to have had a deleterious effect on this value in communities.

\section{Limitations}

The participants in this study were primarily caregivers of students who participated in another component of this study. These caregivers were interested in discussing nutrition, and thus may not represent a broad cross-section within these six First Nation communities. This study was limited by the small numbers of focus group participants relative to the population of each community.

\section{Discussion}

Dietary decisions made by caregivers in these First Nation communities are impacted by sociocultural, environmental, and societal/historical level determinants. In the focus groups, participants described how the food systems in their communities have significantly changed during their lifetime. Traditional practices of accessing food from the land has been restricted and has been attributed to 
colonization. Colonization has resulted in what the Truth and Reconciliation Commission (2015) referred to as cultural genocide:

...the destruction of those structures and practices that allow the group to continue as a group. States that engage in cultural genocide set out to destroy the political and social institutions of the targeted group. Land is seized, and populations are forcibly transferred and their movement is restricted. Languages are banned. Spiritual leaders are persecuted, spiritual practices are forbidden, and objects of spiritual value are confiscated and destroyed. And, most significantly to the issue at hand, families are disrupted to prevent the transmission of cultural values and identity from one generation to the next. (TRC, 2015, p. 1).

This system of devaluing Indigenous cultures has affected food systems in these communities. Participants commented on several factors that have detrimentally affected food systems in their community. These factors include the infringement on, and contamination of, traditional territories; the modernization and marginalization of culture; participation in the mainstream economy; and issues of poverty. Decolonization and the restoration of traditional food systems are offered as a means to revitalizing the food systems in these communities.

\section{Colonization and Contamination of Traditional Territories}

Access to traditional territories in order to exercise treaty rights to hunt and fish has been hindered by regulations imposed by the colonial government (Chan et al., 2014). Focus group participants noted that some freshwater fish and wild game species have declined. The decline in fish can be attributed to overfishing by commercial and sport fishing, as well as from invasive species (Hudson \& Zieglar, 2014). This is compounded by the risk of increased exposure to contaminants associated with consuming freshwater fish and wild game (Davies, 2001). For example, the Guide to Eating Fish in Ontario advises limiting the consumption of pickerel and pike due to mercury (Ministry of the Environment and Climate Change, 2015). These contaminants among fish and game populations are a direct result of industrial pollution, which is a colonial activity. As a result, fewer fish and concerns about contaminants have decreased consumption of traditional foods (Willows, 2005). Additional barriers to hunting and fishing practices include time constraints, the absence of a harvester in the household, lack of equipment, and transportation (Chan et al., 2014).

Harvesting naturally occurring food and medicinal plants from the environment has reportedly declined among the focus group participants. This may be due to a number of factors. There has been a loss of plant habitat not only in the traditional territories but within First Nation reserve boundaries as built environments expand. Environmental contamination and climate change have negatively affected plant growth (Power, 2008). Practices such as controlled burning which releases the seeds of different 
plant species are not occurring as frequently as in the past (Kimmerer \& Lake, 2001). The interdependence of plants and animals is crucial to diverse habitats. A decline in animal species will also bring a decrease in the spread of seeds through animal digestion. Finally, Anishinaabe teachings highlight the importance of maintaining reciprocal relationships with plants, observing that plants must be harvested respectfully in order to flourish (Kimmerer, 2013). This reciprocal relationship must be maintained in order for food and medicinal plants to thrive. These factors may have contributed to the reported decline in the availability of wild berries, as well as other plants used for food.

\section{Modernization and the Marginalization of Culture}

In the past, procuring food from the land through activities like hunting, fishing, and gardening was not only labour intensive, but key to maintaining social and cultural bonds. The rapid transition to predominantly market food has also been influenced by the decreased availability of smaller game and indigenous fish species. Activities such as harvesting berries and raising livestock have also declined due to changes in socioeconomic conditions, whereby more people are involved in the wage economy, and do not have the time to engage in these activities (Power, 2008). These changes in hunting, fishing, harvesting, and gardening practices have resulted in a decline in the reliance on food from the land.

The decline of gardening activities in these First Nation communities may be due to several reasons. These include smaller, rented properties with a backyard reserved for a field bed; the increase in the commercial production of fruits and vegetables (Dorff, 2014); the loss of gardening knowledge due to the increased availability of commercial produce, decreasing the need to garden; the lack of tools needed for gardening activities; the associated cost of plants and tools; and the labour intensity of gardening (Conway \& Brannen, 2014).

The use of the term 'lazy' in regards to meal preparation by some participants can be viewed as another way in which the internalized marginalization of Indigenous people is present in some communities or community members. This label likely stems from a stereotype that has been used to describe Indigenous people e.g., 'lazy Indians' (Lutz, 2009). This stereotype has been internalized by some participants, and may be a way of avoiding responsibility for well-being. Avoiding or refusing to take responsibility is the result of the colonial legacy of the federal government controlling all aspects of the lives of Indigenous peoples in Canada (Richmond \& Ross, 2009). However, using the term 'lazy' in a joking manner can be also seen as an act of resistance to this externally imposed label.

\section{Participation in the Economy and Issues of Poverty}

Dietary decisions are determined by food distribution challenges, namely food insecurity. Socioeconomic status affects food security and participants in this study reported that they rely almost entirely on market foods, and therefore their income directly affects the type and amount of food they can purchase. The quality of store-bought fruits and vegetables is reportedly poor, while processed foods are perceived to be non-perishable and inexpensive. Income also determines whether community 
members can afford a vehicle or whether they will require a taxi to transport them to a grocery store. The closest grocery stores are range between five kilometres and 52 kilometres away from these First Nation communities, and thus additional and costly transportation is necessary in order to obtain market fresh food. Some of the communities have established food banks in order to address food insecurity among low income households.

Participants were knowledgeable about healthy foods but consistently making healthy food choices continues to be a challenge due to reasons such as the proliferation of processed foods. Processed foods are readily available, are perceived to be inexpensive, and can be prepared quickly. Processed foods have a longer shelf life because they contain high amounts of preservatives (Moss, 2013). Less perishable foods are selected because people on limited incomes must have food that can an entire month. In addition, cooking skills have diminished along with the perception that there is not enough time to cook from scratch. The practice of preparing traditional foods may have been lost as a result of family interruptions due to residential schools and the Sixties Scoop. Children's exposure to traditional practices of harvesting food would be significantly impacted by their long-term absence from their family and home community.

\section{Decolonization and the Restoration of Traditional Food Systems}

The importance of local food systems in addressing food insecurity, nutrition and health in Indigenous communities has been recognized (Kuhnlein, 2009). Indeed, Alfred and Corntassel (2005) suggest that Indigenous peoples 'decolonize' their diet with natural food sources as one way to regenerate and transform communities. Participants in this study noted that traditional foods remain crucial to Anishinaabek identity. The communities in this study have initiated activities such as community gardens and community freezers where wild game can be stored and shared within the community. In addition to family hunting practices, these communities also gather together for fall hunting camps. The purpose of these communal hunting camps are to share traditional hunting practices, as well as to assert rights and to maintain stewardship of the land.

The Anishinabek/Ontario Fisheries Resource Centre conducts educational outreach activities in these communities on traditional fish harvesting practices and food preparation. These initiatives are opportunities to revitalize Indigenous food systems by sharing gardening, hunting, and fishing skills by reconnecting to the land and by connecting with other community members. Restoring local food systems moves Indigenous communities towards food sovereignty which can lead to increased access to healthy foods and increased physical activity while reconnecting to the land and supporting the maintenance of cultural identity.

\section{Conclusion}

Ultimately, colonial policies and legislation have resulted in the loss of traditional territories, infringed on Indigenous hunting and fishing rights, and removed people from their lands that once 
provided traditional and nourishing food sources. One of the most significant forces connected to these issues is the legacy of Indian Residential Schools. The Truth and Reconciliation Commission has found that Canada remains systematically, institutionally, and structurally colonial and racist, thus posing ongoing challenges for caregivers that attempt to make healthy dietary decisions in these First Nation communities (TRC, 2012). Some of these challenges are accessing food from the land, having enough money for market foods, and preparing healthy meals from whole foods.

Food systems in these six communities have undergone a rapid transition which have influenced dietary decisions. Participants reported that in the past, food was sourced through traditional activities such as hunting, fishing, gathering, gardening, and raising livestock. At present, however, they reported an almost exclusive reliance on market foods from the grocery store, although traditional foods remain culturally significant, especially for ceremonial feasts. With fewer available small game animals and the scarcity of some indigenous fish species, food insecurity is an issue in these communities. Participants were aware of healthy foods and were concerned about the health effects of a poor diet, but food choices were impacted by the high cost of food, the poor quality of fresh fruits and vegetables, time constraints with less food being prepared from 'scratch', and an overall greater reliance on processed foods.

The economic structure in these communities have also changed with more people being involved in the mainstream economy which limits their time to gather and prepare traditional foods. Dietary decisions were found to be influenced by interpersonal, community, and societal level factors. Despite the permeation of colonialism, these First Nation communities are taking steps to revitalize their food systems through activities such as community gardens, fishing, and community hunt camps. These activities are viewed as opportunities to revitalize Indigenous food systems by reconnecting to the land and reinforcing community and kinship bonds. Cultural practices offer a much needed space where more community members can return to traditional foods, activities and values.

\section{References}

Anishinabek/Ontario Fisheries Resource Centre. (n.d.). About the Centre. Available at: http://www.aofrc.org/aofrc/anishinabekontario-fisher.html

Alfred, T. \& Corntassel, J. (2005). Being Indigenous: Resurgences against contemporary colonialism. Government and Opposition, 40(4), 597-614. https://doi.org/10.1111/j.1477-7053.2005.00166.x

Babbie, E. (1992). The Practice of Social Research. Sixth Edition. California: Wadsworth Publishing Company.

Bartlett, C., Marshall, M., \& Marshall, A. (2012). Two-Eyed Seeing and other lessons learned within a co-learning journey of bringing together indigenous and mainstream knowledges and ways of knowing. Journal of Environmental Studies and Sciences, 2(4), 331-340. https://doi.org/10.1007/s13412-012-0086-8 
Chan, L., Receveur, O., Batal, M., David, W., Schwartz, H., Ing, A., Fediuk, K., Black, A., \& Tikhonov, C. (2014). Food, Nutrition and Environment Study (FNFNES): Results from Ontario (2011/2012). Ottawa: University of Ottawa, 2014.

Charmaz, K. (2006). Constructing Grounded Theory: A Practical Guide Through Qualitative Analysis. London: Sage.

Conway, T. M., \& Brannen, K. (2014). Who is Tending Their Garden? Edible gardens as a residential landscaping choice. Cities and the Environment (CATE), 7(2), 1-22. Retrieved from: http://digitalcommons.lmu.edu/cate/vol7/iss $2 / 10$

Dickason, O.P. \& McNab, D. (2009). Canada's First Nations: A History of Founding Peoples from Earliest Times. Toronto: Oxford University Press.

Davies, K. (2001). EAGLE Project Contaminants in Human Tissues. Assembly of First Nations, Chiefs of Ontario, Health Canada and First Nation Communities. Available at: http://www.chiefs-ofontario.org/node/115

DiGangi, P. (1993). UCCM Fish \& Wildlife Project: Submission to the Royal Commission on Indigenous Peoples. West Bay, Ontario: United Chiefs and Councils of Manitoulin Island. Retrieved from: http://data2.archives.ca/rcap/pdf/rcap-631.pdf

Dorff, E. (2014). The Changing Face of the Canadian Fruit and Vegetable Sector: 1941 to 2011. Statistics Canada, Agriculture Division. Catalogue no. 96-325-X. Retrieved from:

https://www150.statcan.gc.ca/n1/en/pub/96-325-X/2014001/article/11921-eng.pdf?st=9ORJjhIo

Earle, L. (2011). Traditional Indigenous diets and health. National Collaborating Centre for Indigenous Health. Retrieved from:

http://www.nccahccnsa.ca/en/publications.aspx?sortcode=2.8.10\&publication=44

Hudson, J. C., \& Ziegler, S. S. (2014). Environment, culture, and the Great Lakes fisheries. Geographical Review, 104(4), 391-413. https://doi.org/10.1111/j.1931$\underline{0846.2014 .12041 . x}$

Kimmerer, R.W. (2013). Braiding Sweetgrass: Indigenous Wisdom, Scientific kKnowledge and the Teachings of Plants. Minneapolis, MN: Milkweed Editions.

Kimmerer, R. W., \& Lake, F. K. (2001). The role of indigenous burning in land management. Journal of Forestry, 99(11), 36-41. https://doi.org/10.1093/jof/99.11.36

Kuhnlein, H. (2009), Why are Indigenous Peoples' food systems important and why do they need documentation? In Kuhnlein, H. V., Erasmus, B., \& Spigelski, D. (Eds.), Indigenous Peoples' Food Systems: The Many Dimensions of Culture, Diversity and Environment for Nutrition and Health (pp. 1-7). Quebec: Food and Agriculture Organization of the United Nations (FAO). Retrieved from: http://www.fao.org/docrep/pdf/012/i0370e/i0370e00.pdf

Lutz, J.S. (2009) “Making the Lazy Indian”. In Makúk: A New History of Aboriginal-White Relations. Vancouver: UBC Press.

Ministry of Environment and Climate Change. (2015). Guide to Eating Ontario Fish, 2015-2016. Twenty-eighth edition, revised.. Toronto: Queen's Printer for Ontario. Retrieved from: https://dr6j45jk9xcmk.cloudfront.net/documents/4460/fishguide2015-final-aoda-en-final.pdf 
Mosby, I. (2013). Administering colonial science: Nutrition research and human biomedical experimentation in Indigenous communities and residential schools, 1942-1952. Social history, 46(1), 145-172. https://doi.org/10.1353/his.2013.0015

Moss, M. (2013). Salt Sugar Fat: How the Food Giants Hooked Us. New York: Random House.

National Indigenous Health Organization. (n.d.). Terminology Guidelines. Retrieved from: http://www.naho.ca/publications/topics/terminology/?submit=view

Power, E. M. (2008). Conceptualizing food security for Indigenous people in Canada. Canadian Journal of Public Health/Revue Canadienne de Sante'e Publique, 99(2), 95-97. Available from: https://www.jstor.org/stable/41995048

Richmond, C. A., \& Ross, N. A. (2009). The determinants of First Nation and Inuit health: A critical population health approach. Health \& Place, 15(2), 403-411. https://doi.org/10.1016/j.healthplace.2008.07.004

Statistics Canada (2008) Indigenous Peoples in Canada in 2006: Inuit, Métis and First Nations, 2006 Census. Catalogue no. 97-558-XIE. Retrieved from: http://www5.statcan.gc.ca/access_acces/alternative_alternatif.action?l=eng\&k=4736\&loc=http://w ww12.statcan.ca/census-recensement/2006/as-sa/97-558/pdf/97-558-XIE2006001.pdf

Truth and Reconciliation Commission of Canada. (2012). Canada, Aboriginal Peoples, and Residential Schools: They Came for the Children. Winnipeg: Author. Retrieved from: http://www.trc.ca/websites/trcinstitution/index.php?p=893

Truth and Reconciliation Commission of Canada. (2015). Final Report of the Truth and Reconciliation Commission of Canada. Volume One: Summary. Honouring the Truth, Reconciling for the Future. Toronto: James Lorimer \& Company, Ltd.

Willows, N. D. (2005). Determinants of healthy eating in Indigenous peoples in Canada: the current state of knowledge and research gaps. Canadian Journal of Public Health, 96(3), S32-S36. https://dx.doi.org/10.17269/cjph.96.1503

Willows, N. D., Hanley, A. J., \& Delormier, T. (2012). A socioecological framework to understand weight-related issues in Indigenous children in Canada. Applied Physiology, Nutrition, and Metabolism, 37(1), 1-13. https://doi.org/10.1139/h11-128 